\title{
ESENSI AJARAN MORALITAS DALAM TUTUR JATISWARA
}

\author{
Oleh: \\ Ni Made Surawati ${ }^{1}$, Ni Nyoman Sri Winarti ${ }^{2}$, A.A. Putra Dwipayana ${ }^{3}$ \\ madesurawati@yahoo.co.id ${ }^{1}$ \\ Fakultas Pendidikan Universitas Hindu Indonesia \\ Denpasar
}

Proses Review 15-25 September, Dinyatakan Lolos 28 September 2019

\begin{abstract}
Literary works are a source of knowledge especially in Hinduism. In this study a literary work entitled Tutur Jatiswara was the object of research. The text of Tutur Jatiswara is a literary work that contains the behavioral teachings and texts of Tutur Jatiswara including literary works that are classified as young by describing them in Balinese language. The beauty of the speech style of the language delivered at the beginning of the text, the content, and also the analysis of the meaning of beauty contained is the beauty of the relationship between parents and children, where parents are always a role model, and become guidelines for their children, because people parents also will begin to educate the characters, mental children to become suputra children, the importance of the role of parents in shaping the child's self, so that later their children become someone who has a code of conduct (moral) in this life.
\end{abstract}

Keywords: Morality, Tutur Jatiswara, Hinduism

\begin{abstract}
Abstrak
Karya sastra adalah sumber pengetahuan terutama dalam agama Hindu. Dalam penelitian ini dikaji sebuah karya sastra berjudul Tutur Jatiswara. Teks Tutur Jatiswara adalah sebuah karya sastra yang berisi ajaran perilaku dan teks-teks. Keindahan tutur gaya bahasa yang disampaikan pada awal teks, isi, dan juga analisis terhadap makna keindahan yang dikandung merupakan suatu keindahan dari hubungan antara orang tua dengan anak, di mana orang tua yang selalu menjadi suritauladan, dan menjadi pedoman bagi anak-anaknya, karena orang tua juga yang akan mengawali untuk mendidik karakter-karakter, mental anak agar menjadi anak yang suputra, pentingnya peranan orang tua dalam membentuk jadi diri sang anak, agar kelak anaknya menjadi seorang yang mempunyai tata tingkah laku (moral) dalam kehidupan ini.
\end{abstract}

Kata Kunci: Moralitas, Tutur Jatiswara, agama Hindu 


\section{PENDAHULUAN}

Proses globalisasi yang ditandai dengan kemajuan teknologi komunikasi dan transportasi telah meningkatkan pertemuan antar budaya melalui televisi, internet, buku, majalah, koran dan beberapa media yang lainnya. Dalam pertemuan antar budaya tersebut nilai budaya yang mengiringi arus globalisasioleh masyarakat seiring dilihat dan diambil bukan dari segi aspek positifnya, yakni penguasaan sain dan teknologi, tetapi hanya pada gaya hidup global. Sementara itu nilai-nilai yang terkandung dalam budaya lama, tidak mampu bertahan ketika berhadapan dengan nilai budaya baru dan terpinggirkan dari fungsinya sebagai rujukan tatanan nilai kehidupan bermasyarakat, karena dianggap tidak sesuai lagi dengan tuntutan perubahan dan ketidak mampunya membawa perbaikan dan memecahkan permasalahan yang timbul dalam masyarakat.

Peran teknologi dalam mempengaruhi perubahan manusia bukanlah sesuatu hal yang perlu dipertanyakan lagi, manusia tidak akan mampu hidup tanpa teknologi. Lebih lanjut Martono (2014) menyatakan tentang analisis Marx mengenai teknologi dikaitkan dengan peran teknologi sebagai faktor produksi. Bagi Marx, teknologi telah melahirkan ketidaksetaraan atau ketimpangan sosial dalam masyarakat, teknologi lebih di maknai sebagai alat yang dapat dipakai manusia untuk mencapai kesejahteraan. Ketika tidak semua manusia mampu menguasai teknologi ini, maka yang Seiring dengan proses pembangunan menuju masyarakat yang maju dalam menguasai teknologi dan sain saat itu juga bangsa ini dihadapkan pada berbagai tantangan dan hambatan. Tantangan dan hambatan tersebut adalah perkembangan perilaku masyarakat dalam kehidupan semakin jauh dari idealnya, yaitu moral manusia yang semakin memudar. Secara spesifik dapat dilihat pada masyarakat terutama yang ada di perkotaan, telah berada dalam keadaan mencemaskan, antara lain dengan telah meningkatnya perbuatanperbuatan yang tidak terpuji seperti perbuatan korupsi, kecanduan dan peredaran narkotika, perjudian, penjarahan, pembegalan, perampokan, bunuh diri, pembunuhan, dan sebagainya yang semakin merajalela. Semua itu pertanda bahwa keadaan moral warga telah berada di dalam kondisi yang sangat menyedihkan di seluruh lapisan masyarakat.

Dengan beberapa fenomana yang tengah terjadi dikalangan masyarakat dewasa ini, khususnya di Bali, umat Hindu perlu memahami, mendalami bahkan menghayati ajaran agamanya dengan baik, sehingga dapat mengetahui etika, moral atau norma-norma tata susila yang berlaku dalam masyarakat, disamping mengetahui mana yang boleh dilakukan dan mana yang patut dihindari. Karena itu mereka semestinya patut mengerti dan menguasai ajaran agamanya secara baik dan benar, yang meliputi Tattwa atau Filsafat, Susila atau Etika/ Moral, dan Upacara atau Ritual agama Hindu (Suhardana, 2008: 17). Secara visual ajaran agama Hindu adalah kegiatan dari Upacara atau ritual agamanya, mereka tidak harus menguasi masalah Upacaranya saja, tetapi juga yang terpenting adalah mengerti akan perihal Tattwa dan pola tingkal laku yang sering disebut dengan Susila atau moral. Agama adalah dasar tata susila yang kokoh dan kekal, ibarat landasan bangunan, di mana suatu bangunan harus didirikan. Jika landasan itu tidak kuat, maka mudah benar bangunannya roboh. Demikian juga halnya dengan tata susila, bila tidak dibangun di atas dasar agama sebagai landasan yang kokoh dan kekal, maka tata susila itu tidak mendalam dan tidak meresap dalam diri pribadi manusia. Tata susila yang berdasarkan ajaranajaran agama atau yang berpedoman atas ajaran kerohanian sebagai yang terdapat di dalam kitab suci Upanisad (Wedanta), Tattwa-Tattwa (Tuturtutur), mulai dengan dalil atau aksioma yang mengakui tunggalnya Jiwatma (roh) semua makhluk dengan Brahman atau Paramatma, yang tutur di Bali sering menyebut dengan nama Paramasiwa (Hyang Widhi Wasa) (Mantra, 2016: 5). Tata Susila dapat membina watak manusia agar bisa menjadi anggota keluarga atau anggota masyarakat yang baik, dan menjadi manusia yang berkepribadian mulia, serta dapat membimbing mereka untuk mencapai kebahagiaan.

Dalam abad perkembangan teknologi dan sain ini, sudah selakyaknya pendalaman ajaran agama diarahkan pada pola berpikir kearah 
reorientasi penghayatan ajaran agama Hindu itu sendiri dan melihat ajaran agama Hindu sebagai ilmu kebijakan yang dapat menuntun umat manusia menuju pada kehidupan yang Jagadhita. Berbicara masalah moral sesungguhnya banyak materi yang harus dibahas diantaranya Tattwa, Etika, Upacara, Desa Kala Patra, Sampat Asuri Sampat, Triguna dan lainnya. Mengenai literatur yang dapat dipakai sebagai pedoman dalam mencapai tujuan agama, tujuan manusia, dan tujuan Agama Hindu yaitu Moksartam Jagadhitaya Ca Iti Dharma, dengan literatur yang cukup banyak seperti Sarasamuccaya, Wrespati Tattwa, Makna Agama dalam kehidupan, Manawa Dharmasastra, dan yang lainnya (Suatama, dkk, 2007 : 30).

Seluruh literatur-literatur yang disebutkan di atas merupakan suatu ajaran yang 5 wajib dilaksanakan oleh umat beragama, ajaranajaran tersebut termuat dalam kitab suci Agama Hindu. Sumber Ajaran Agama Hindu adalah kitab suci Weda, yaitu kitab yang berisikan ajaran kesucian, yang diwahyukan Ida Sang Hyang Widhi Wasa melalui para Maha Rsi (Satria, dkk, 2016 : 12). Selain dari Weda yang merupakan sumber utama dari ajaran Agama Hindu, ada juga sumber-sumber lain yang merupakan sumber ajaran Agama Hindu itu sendiri yaitu tafsir-tafsir yang berkembang dan juga dijadikan sumber ajaran Agama Hindu. Salah satunya yang dijadikan sebagai sumber ajaran Agama Hindu dalam kehidupan masyarakat adalah lontar-lontar yang terdapat di Bali. Pada dasarnya lontar-lontar tersebut tidaklah secara mentah menyerap ajaran Weda, namun telah mengalami suatu seleksi dan penyaringan yang bijaksana dan disesuaikan dengan alam pikiran dan Desa Kala Patra setempat, namun esensi ajarannya masih tetap sama.

Mengingat naskah-naskah kuna pada saat itu ditulis di atas daun lontar yang tidak dapat bertahan lama, maka naskah-naskah tersebut dirawat dengan baik. Rusaknya sebuah naskah sama artinya dengan kehilangan salah satu sumber dari pengetahuan. Dari sekian banyak naskah-naskah yang menafsirkan ajaran Agama Hindu terdapat sebuah lontartentang Tutur Jatiswara.

Dalam teks Tutur Jatiswara terdapat dan menguraikan pokok-pokok pikiran yang dapat menjadi pedoman dalam kehidupan ini agar selalu berprilaku yang sewajarnya, adapaun pokok pikiran tersebut antara lain: 1) Sang Hyang Jiwa, yaitu tentang asal jiwa tersebut adalah Ida Sang Hyang Widhi, kita harus selalu sujud bakti terhadap jiwa, sehingga akan mendapatkan kebahagiaan. 2) Laksana Dharma, berbuatlah dharma terhadap setiap orang tanpa mengharapkan imbalan. 3) Sang Hyang Pati (Kalamretyu), yang menyebabkan mahkluk hidup itu mati, maka selalulah berbuat baik, karena kita tidak akan tahu kapan datangnya kematian, maka selalu berbuat kebajikan. 4) Karmapata, sepuluh macam perbuatan untuk mengendaliakan diri. 5) Manumadi, yang mana menyatakan penjelmaan pada saat ini adalah hasil dari perbuatan yang kita lakukan sebelumnya. 6) Darma, perbuatan dharma itu adalah perbuatan untuk mendapatkan kebahagiaan di dunia dan akhirat. 7) Sang Hyang Agama, yaitu suatu ajaran yang menyebabkan manusia menemui kebahagiaan lahir dan batin. Teks Tutur Jatiswara pada hakikatnya memberikan wejangan atau nasihat agar selalu bertingkah laku yang baik dan benar.

\section{METODE PENELITIAN}

Tutur Jatiswara merupakan suatu karya sastra yang bejenis tutur, pokok pembahasannya berisikan tentang nasihat ayah (orang tua) kepada anaknya agar selalu patuh dan bertingkah laku yang baik sesuai dengan petunjuk yang tersurat dan tersirat dalam sastra-sastra agama. Dilihat dari isinya yang memuat ajaran mengenai pengendalian diri melalui ajaran tingkah laku untuk dapat hidup di dunia ini dengan bahagia yang berlandaskan dengan konsep-konsep ajaran keagamaan.

Melalui metode penelitian kualitatif deskriptif dapat dipahami bahwa terdapat uraian pokok-pokok pemikiran yang dapat di jelaskan sebagai berikut: Sang Hyang Jiwa, Laksana Dharma, Sang Hyang Pati (Kalamretyu), Karmapata, Manumadi, Dharma, dan Sang Hyang Agama. Penjelasannya pokok pikiran tersebut dapat dijelaskan sebagai berikut. Sang Hyang Jiwa, menguraikan tentang bagaimana Jiwa tersebut, di mana penjelasannya, yang 
menyebabkan manusia bisa hidup. Jiwa berasal dari Ida Sang Hyang Widhi dan patut di sembah. Segala mahluk hidup di dunia ini dihidupkan oleh jiwa. Kita harus selalu sujud bakti terhadap jiwa, sehingga kita akan mendapatkan kebahagiaan. Laksana Dharma, menguraikan tentang perbuatan. Tidak ada perbuatan yang lebih utama dari pada berbuat dharma, namun sangat sulit agar mampu berbuat dharma, bila kita berbuat dharma terhadap orang miskin dengan mengharapkan imbalan, maka kita tidak akan jadi berdharma.

Orang budiman akan selalu kukuh teguh melaksanakan dharma karena itu sudah tersirat dalam sastra agama. Sang Hyang Pati (Kalamretyu), menguraikan tentang kematian setiap mahkluk hidup. Penjelasannya yang menyebabkan mahkluk mati. Namun yang mati itu adalah raganya, bukan jiwanya. Jiwa tersebut akan hidup di alam niskala dengan membawa hasil perbuatan yang diperbuat didunia. Melaksanakan upacara yang besar tidak akan dapat mengubah hasil perbuatan. Maka dari itu berbuat baiklah selagi kita hidup.

Karmapata, merupakan sepuluh macam perbuatan untuk mengendalikan diri, pembagaiannya terdiri atas tiga perbuatan untuk mengendalikan pikiran, empat perbuatan untuk mengendalikan perkataan, dan tiga perbuatan untuk mengendalikan tingkah laku. Manumadi, menyebutkan bahwa tidak ada yang lebih utama dari menjelma menjadi manusia. Karenanya berbahagialah kita dapat menjelma menjadi manusia walau nista sekalipun. Sangat sulit mendapatkan penjelmaan menjadi manusia.

Penjelmaan menjadi manusia bagaikan tangga untuk naik pada taraf kehidupan untuk bersatu dengan asalnya. Dharma, itu yang namanya perbuatan untuk mendapatkan kebahagiaan di dunia dan akhirat. Orang yang berbuat dharma itu bagaikan air menggenangi pada pohon tebu. Tidak tebu saja yang mendapatkan air, namun tumbuhan yang dekat dengannya juga akan merasakan genangan air itu. Sang Hyang Agama, dalam pokok pikiran ini menguraikan tentang bahwa di dunia ini banyak ada agama. Masing-masing agama menempuh jalannya sendiri sesuai dengan keyakinannya, namun tujuannya adalah mencari yang satu yaitu Tuhan.

\section{HASIL PENELITIAN TEKS TUTUR JATISWARA}

\subsection{Tema Teks Tutur Jatiswara}

Tema adalah suatu pokok persoalan atau pokok pikiran yang menjadidasar suatu karya sastra. Menurut Sukada (1987: 70) tema tidak lain adalah ide pokok, ide sentral atau ide yang dominan dalam karya sastra. Menurut Brooks (dalam Tarigan, 1984: 125) tema adalah pandangan hidup yang tertentu dan perasaan tertentu mengenai kehidupan, rangkaian nilainilai tertentu yang membentuk atau membangun dasar atau gagasan utama dari suatu karya sastra. Sutrisno (dalam Duani, 2013: 77) untuk menentukan sebuah tema dalam sebuah

karya sastra, seorang pembaca harus membaca karya sastra itu secara berulangulang dengan seksama dan cermat.

Tema yang terdapat dalam teks Tutur Jatiswara terlihat dari pengarang menyampaikan maksudnya dalam membuat tulisan teks Tutur Jatiswara. Seperti yang terdapat dalam kutipan dibawah ini:

“......ngranayang cĕning nĕpukin karahaywan, disakala niskala, déning cĕning subĕ ngĕlah lakșana jělé mĕlah ané patut lakșanayang cĕning dijagaté, běbĕkĕlan cĕningé manumadi, maadan karmaphala, nanghing bapa patut masih midarthayang lakșanané ané sube lakșanayang bapa, makadi makolihang karahaywan, apang ada anggon cĕning paimbangimbangan waluya pakukuh paincěpan....."

(Tutur Jatiswara, hal. 2)

\section{Terjemahan:}

“....sebabnya engkau menemukan
kebahagiaan, di dunia-akhirat,
karenaengkau sudah mempunyai prilaku
baik dan buruk yang patut engkau
lakukan di dunia, merupakan bekal saat
engkau menjelma, yang disebut
karmaphala tetapi ayah ingin juga
menjelaskan perbuatan yang telah ayah
perbuat, seperti (yang) mendapatkan
kebahagiaan, supaya ada bahan


pertimbangan bagimu, sebagai peneguh konsentrasi......"

Dicermati pada kutipan teks Tutur Jatiswara diatas, teks ini memaparkan tema atau ide pokok yang disampaikan oleh pengarangnya berdasarkan dengan ajaran agama Hindu tentang berperilaku yang baik dan benar, supaya kelak akan mendapatkan kebahagiaan, kedamaian di dunia dan akhirat. Jadi tema yang terkandung di dalam teks Tutur Jatiswara adalah Prilaku yang sesuai dengan ajaran agama niscaya akan mencapai Moksartham Jagadhita Ya Ca Iti Dharma.

\subsection{Ajaran Moralitas dalam Teks Tutur Jatiswara}

Kata moral selalu mengacu pada baik buruknya manusia. Moral berasal dari bahasa latin, "mores" yaitu jamak dari kata mos yang berarti adat kebiasaan. Di dalam kamus besar bahasa Indonesia dikatakan bahwa moral adalah penentuan baik buruk suatu perbuatan atau kelakuan, selanjutnya moral dalam arti istilah adalah suatu istilah yang digunakan untuk menentukan batas-batas dari sifat, perangai, kehendak, pendapat atau perbuatan yang secara layak dapat dikatakan benar, salah, baik dan buruk (Atmaja, dkk. 2010: 9).

Dalam teks Tutur Jatiswara memuat tentang ajaran moral. Merujuk pada teori hermeneutika yang digunakan dalam penelitian ini adalah bertujuan untuk memahami isi ajaran yang terkandung di dalam karya sastra khususnya teks Tutur Jatiswara dengan cara menafsirkan atau menginterpretasi karya sastra tersebut, yang mana sangat banyak mengandung pedoman ajaran-ajaran agama tentang bertingkah laku yang baik dan benar yang termuat di setiap kalimatkalimat dalam karya sastra, maka dari pada itu karya sastra Tutur Jatiswara perlu di interpretasikan untuk mendapatkan kejelasan dari karya sastra itu sendiri. Demikian juga tentunya untuk dapat memahami isi dari pemikiran Pengarang dan sesuatu yang ingin disampaikan kepada para pembaca melalui karya sastra teks Tutur Jatiswara yang berupa esensi ajaran moral.

Isi pemikiran pengarang yang ingin disampaikan kepada para pembaca mengandung suatu ajaran moral dalam teks Tutur Jatiswara, di mana hal tersebut yang merupakan pokok pembahasan dari isi teks Tutur Jatiswara. Adapun kandungan tentang wejangan ajaran moral dalam teks Tutur Jatiswara, seperti kutipan berikut:

“.......Tusing patut makadi bapa nguduh cĕning apang mĕlakșana kéné

kéto, ngĕranyang cĕning nĕpukin karahaywan, disakala niskala, déning cĕning suba ngĕlah lakșana jělé mĕlah ané patut lakșanayang cĕning di jagaté, bĕbĕkalan cĕningé manumadi, madan karmaphala, nanging bapa patut masih midartayang laksanané ané subĕ lakșanayang bapa, makadi makolihang karahaywan, apang ada anggon cĕning paimbangimbangan, waluya pakukuh paincěpan........."

(Tutur Jatiswara, hal. 2).

\section{Terjemahan:}

“........Tidak selayaknya seperti ayah (saya) menyuruh kamu (anakku)agar berprilaku ini-itu, sebabnya engkau menemukan kebahagiaan di duniaakhirat, karena engkau sudah mempunyai prilaku baik dan buruk yang patut engkau lakukan di dunia, merupakan bekal saat engkau menjelma, yang disebut karmaphala tetapi ayah ingin juga menjelaskan perbuatan yang telah ayah perbuat, seperti mendapatkan kebahagiaan, supaya ada bahan pertimbangan bagimu, sebagai peneguh konsentrasi........"

Dari kutipan di atas, Pengarang sendiri mempunyai keinginan untuk menyampaikan sesuatu yang berguna, tentang bagaimana berprilaku baik dan benar untuk menemukan kebahagiaan di dunia dan akhirat, penyampaian yang disampaikan oleh pengarang merupakan suatu bahan pertimbangan berprilaku baik dan benar kepada para pembaca dalam melakukan sesuatu yang akan diperbuat. seperti kutipan di atas menunjukan bahwa peranan orang tua sangat berpengaruh kepada anaknya, di mana peranan orang tua sangat diperlukan dalam mendidik mental dan tingkah laku dari anaknya 
untuk dapat berprilaku yang patut untuk dilaksanakan sesuai dengan kaidah dan normanorma yang berlaku di masyarakat, baik itu yang diwejangkan oleh orang-orang yang budiman, di dalam sastra agama, maupun sumber-sumber literatur atau kepustakaan yang lainnya, karena tidak ada salahnya jika mematuhi nasehat, wejangan, ataupun petuah yang diberikan, itu semua dikarenakan untuk menemukan kebahagiaan di dunia ini. seperti kutipan teks Tutur Jatiswarakutipan berikut ini:

“........ Ĕda pěsan lakșanayanga lakșanané ané kalarang bahan sang

prajñan. Linyok pada sang prajñan makadi bobab agamané nyĕritayang ada suarga naraka, tusing mapikolih lakșananné jĕlé mĕlah, tusing ada jěléné cĕning ngugu pangandikan sang prajñan ngimpasin lakșanané jĕlé........"

(Tutur Jatiswara, hal. 22)

\section{Terjemahan:}

“.......Jangan diperbuat perbuatan yang dilarang oleh orang yang

budiman. Dusta terhadap orang budiman seperti halnya bohong kepada

agama yang menjelaskan adanya sorga neraka, tidak berpahala perbuatan baik dan buruk, tidak ada salahnya anakku mempercayai apa kata orang budiman dan menghindari perbuatan yang buruk........."

Dari kutipan di atas menunjukan bahwa teks Tutur Jatiswaramenekankan pada prinsip tentang bertingkah laku (moral) yang di ajarkan oleh orang-orang prajnyan (budiman), sehingga perlunya perhatian yang memang benar-benar untuk menyikapi bagaimana sikap anak-anak agar tidak menyimpang dari ajaran agamanya khususnya ajaran tentang bertingkah laku yang baik dan benar. Pengarang juga menyatakan bahwa teks Tutur Jatiswara ini dibuat sebagai pedoman yang baik sekali bila dipakai bacaan bagi anak-anak,seperti terdapat dalam kutipan berikut:

“.........Karasayang antuk panampén manahé nambĕt, waluya jati pisan aswara sastra drésta punika, mahawinan kadi mangkin mĕlĕd pisan

manahé ngardinin cakĕpan puniki, déning patut pisan kanggén

wawacénan antuk alit-alit sané wĕnang........."

(Tutur Jatiswara, hal. 1).

\section{Terjemahan:}

“.........Dirasakan serta ditanggapi dengan pikiran yang bodoh, seperti

(Sesungguhnya) satu kata dengan sastradresta itu, sebabnya sekarang ini

ingin sekali hasrat (saya) untuk membuat tulisan ini, karena baik sekali

dipakai bacaan bagi anak-anak yang berminat........"

Dari penjelasan kutipan di atas, memang benar karya sastra Tutur Jatiswara membahas tentang ajaran moral, tujuan dari pengarang adalah memberikan sesuatu yang berguna kepada audience atau pembaca agar dapat digunakan untuk mencapai tujuan kehidupan yang berbahagia di dunia ini. Konsep ajaran moral dalam teks tutur Jatiswara terdiri dari beberapa konsep ajaran yaitu: (a) Ajaran Tat Twam Asi, (b) Ajaran Karma Marga (c) Ajaran Tapa, (d) Ajaran Trikaya Parisudha, (e) Ajaran Dharma, (f) Ajaran karmaphala, (g) Ajaran Punarbhawa, dan (h) Ajaran Sang Hyang Agama (i) Ajaran Bhakti Kepada Catur Guru. Keseluruhan konsep-konsep ajaran tersebut diungkapkan menjadi satu kesatuan yang tidak dapat terpisahkan dan apabila dipahami dengan baik dan benar akan memperkuat dan memperteguh sraddha bhakti setiap orang yang ingin mendalaminya, terutamanya bagi Umat Hindu.

\section{PENUTUP}

Dilihat dari sudut pandang isi teks Tutur Jatiswara, mengandung aspekkeindahan jika memahami dan masuk kedalamnya (membacanya) seakan-akan ada sesuatu hal atau sesuatu menarik yang ingin disampaikan oleh pengarang kepada pembaca, bahwa teks Tutur Jatiswara tersebut ingin menyampaikan sesuatu agar para pembaca mengetahui akan kebenaran yang ingin disampaikan, terlebih- 
lebih teks Tutur Jatiswara tersebut mudah untuk di mengerti karena teksnya berbahasakan bahasa Bali Alus dan Kepara (Andap) atau bahasa Bali yang sering digunakan dalam percakapan sehari-hari, selain itu cara penyampaiannya disimbolkan dengan petuahpetuah, nasihat-nasihat yang disampaikan oleh orang tua (ayah) kepada anaknya. Keindahan tutur gaya bahasa yang disampaikan pada awal teks, isi, dan juga analisis terhadap makna keindahan yang dikandung merupakan suatu keindahan dari hubungan antara orang tua dengan anak, di mana orang tua yang selalu menjadi suritauladan, dan menjadi pedoman bagi anak-anaknya, karena orang tua juga yang akan mengawali untuk mendidik karakterkarakter, mental anak agar menjadi anak yang suputra, pentingnya peranan orang tua dalam membentuk jadi diri sang anak, agar kelak anaknya menjadi seorang yang mempunyai tata tingkah laku (moral) dalam kehidupan ini.

\section{DAFTAR PUSTAKA}

Agastia. Ida Bagus. 1994. Kesusastraan Hindu Indonesia. Denpasar: Yayasan Dharma Sastra. Afriadi. Atmaja. Jiwa. 1988. Masyarakat dan Sastra. Denpasar: Himsa

Atmaja. I Made Nada, dkk. 2010. Etika Hindu. Surabaya: Paramita.

Donder. I Ketut. 2005. Esesnsi Bunyi Gamelan dalam Proses Ritual Hindui. Surabaya: Paramita.

Kadjeng. I Nyoman, dkk. 2003. Sarasamuccaya, Dengan Teks Bahasa Sanskerta dan Jawa Kuna. Surabaya: Paramita.

Karmini. Ni Nyoman. 2011. Teori Pengkajian Prosa Fiksi dan Drama. Denpasar: Pustaka Larasan. Martono. Nanang. 2014. Sosiologi Perubahan Sosial: Persepektif Klasik, Modern, Posmodern, dan Poskolonial (Edisi Revisi). Jakarta: Rajawali Press.

Ida Bagus Udara. 1983. "Anggah-Ungguhing Bahasa Bali dan Peranan Sebagai Alat Komunikasi bagi Masyarakat Suku Bali". Skripsi Jurusan Bahasa dan Sastra Bali UNUD Denpasar. Pariatna.

Pudja. I Gde. 1985. Pengantar Agama Hindu Jilid I Untuk Perguruan Tinggi. Jakarta: Mayasari.

Suprayoga dan Tabroni. 2001. Metode Penelitian Sosial-Agama. Bandung: PT. Remaja Rosdakarya. Sura. I Gede. 1985. Pengendalian Diri dan Etika dalam Ajaran Agama Hindu. Denpasar: Direktorat Jendral Bimas Hindu dan Budha.

I Nengah. 1986. Sor Singgih Basa Bali. Denpasar: Rikha Dewata. Tirta.

Putu Arya. 1987. Antologi Esai dan Kritik Sastra. Flores NTT: Nusa Indah. Wellek. Rene dan Austin Warren. 1990. Teori Kesusastraan. Jakarta: PT. Gramedia.

Watra. I Wayan. 2006. Filsafat Manusia Dalam Persfektif Hindu. Surabaya: Paramita.

Wiana. I Ketut, 2004. Mengapa Bali disebut Bali?. Surabaya: Paramita 